\title{
nature
}

1 January 1998 Volume 391 Issue no 6662

\section{Fading pan-European visions?}

Making the most of European collaboration would seem to be sensible as pressures on research budgets intensify. But those with the power to pursue that agenda are failing to do so.

A bout forty years ago, a grand moment arrived for those visionaries who, since 1945, had been working to increase economic cooperation between European states: the establishment of the common market and the European Economic Community, signified in the Treaty of Rome of 1957. In the post-war years, the idea that science should also be supported in a pan-European manner was almost taken for granted. But, at the time of the treaty, Europe was more preoccupied with a growing technology gap and the 'brain drain' to the United States, and the main focus of attention was on technologyoriented research projects in the aerospace, space and nuclear fields.

That was a shame for fundamental science. For the treaty incorporated the creation of the European Commission, based in Brussels. And for all the charges that have been laid against it, the commission is unique and valuable in at least one respect: it contains a group of bright people mandated by governments to think supranationally, that is, to seek out and nurture the added value that can come out of panEuropean collaboration.

At the outset, science was unfortunately not on their agenda. Indeed, to many scientists, the word 'Europe' is a professional irrelevance. After all, ideas and techniques know no geographical boundaries, and so long as researchers receive funds and establish good collaborations, what else matters? But even putting aside the political goal of supporting weaker regions in their scientific ambitions, and concentrating on the pursuit of science at its verybest, the benefits of European collaboration need be no greater than that with the United States to make it worth pursuing.

\section{Enthusiasm}

That much is clear from the enthusiasm with which researchers apply for the 'training and mobility' segment of the European Union (EU)'s Framework programme in research and development — the only part in which, in the pursuit of encouraging the mobility of European researchers, the commission is allowed to support basic research, even on topics of no immediate economic value. So much is also clear from the positive perspectives and contacts that are formed as evaluators and peer reviewers assess EU research programmes.

A new player in European science politics is the European Parliament which, following the signing of the Maastricht Treaty, now has the capacity substantially to influence scientific policy - as it achieved last week in the scrutiny of the European Commission's proposed fifth Framework programme (see page 3). But the parliament's priorities appear to be the scrutiny of strategic research — and from many perspectives, reflecting the interests of individual politicians and the representations of lobby groups, some of them highly critical of science.

A look elsewhere around Europe today suggests that, although the spirit of Europe's science community is willing, the collaboratively minded flesh of its paymasters is not. No funding institution has both a confident mandate and the clout required successfully to pursue the full added value of pan-European science.

The landscape of facilities highlights the trend. Existing facilities are thriving, but what of the future? CERN, one of the triumphs of scientific collaboration in Europe, is turning into a world facility - its European identity will now be progressively buried under the realities of maintaining Japanese and US funding - and why not, if that is the natural condition of high-energy physics? The Institut Laue-Langevin and the European Synchrotron Radiation Facility (ESRF) in Grenoble are both performing well. But plans for new synchrotrons in particular are developing at national or ad hoc multilateral levels.

As pressures on funding intensify, the value of collaboration and complementarity - in skills, in techniques, in the sharing of large and medium-sized facilities — across Europe should be growing. Yet, in the absence of a substantial role for the commission in fundamental science, what are other paymasters doing about it? An unofficial grouping of European heads of research councils (Eurohorcs) meets every six months to discuss matters of common concern, such as scientific fraud. These individuals control more than 90 per cent of the scientific funding in Europe. Yet they distance themselves from any attempt actively to coordinate or develop activities at a pan-European level.

\section{Hope}

The final existing hope for Euro-enthusiasts is the European Science Foundation (ESF), a quasi-independent body funded by national research agencies. Here, if anywhere, is where the pan-European agenda should be being pursued. And to an extent it is. Small collaborative networks and programmes have been established in life sciences, physical sciences and social sciences. 'Euroconferences' are organized jointly with the commission. But the ESF remains a small group of people, located relatively inaccessibly in Strasbourg.

Furthermore, the ESF's role is undermined by the ambivalence of its paymasters, those very bodies represented by the Eurohorcs, about what that role should be. Take, for example, large facilities. Occasionally the foundation is given a key role, as it was in acting as a midwife for the ESRF during the critical phases of its design, and as it is in the current development of proposals for a European Spallation Source (for neutrons) and 100-tesla magnetic field facility. But individual states meanwhile proceed with new neutron sources with scant reference to wider European considerations.

Yet national research agencies have mixed feelings about the ESF taking on a more systematic role in such areas, while the foundation itself is nervous about upsetting them. This confusion as to whether the national agencies are enlightened sponsors, or paymasters in search of direct returns, is a crucial problem for the ESF, which has also failed to position itself as a body that represents Europe's research scientists.

Is the relative lack of support for pan-European research a shortterm problem? If one assumes that the ESF is the only body capable of pursuing such an agenda, then the role of its senior figures in maintaining credibility and a reputation for quality is crucial. That is a challenge for the ESF's incoming director-general, Enric Banda. An enlightened goal for the foundation's paymasters would be to build its formal role in making the best of European complementarity, and to give it the mandate to speak out on the obstacles and opportunities facing Europe's researchers. As national agencies, facing budgetary squeezes, seek to retain maximum control over their budgets, the foundation faces an uphill battle in carving a role for itself. But it represents the only opportunity for those trying to make the best of Europe's basic science. 